\title{
Functional Outcomes and Quality of Life After Ankle Fracture Surgically Treated: A Systematic Review
}

\author{
Viviane Ribeiro de Ávila, Teresa Bento, Wellington Gomes, \\ José Leitão, and Nelson Fortuna de Sousa
}

\begin{abstract}
Context: Ankle fractures (AFs) are the most common fractures of the lower limbs found in emergency services. Approximately $53 \%$ of these fractures are unstable and treated surgically. Objective: To conduct a systematic review evaluating functional outcomes and quality of life of patients with AFs surgically treated. Evidence Acquisition: A systematic review was conducted in accordance with the Preferred Reporting Items for Systematic reviews and Meta-Analyses statement. Five electronic databases were searched, without any limit on publication dates. Only patients with an unstable AF that was surgically treated were included; functional outcomes and the quality of life were controlled by the 36-Item Short-Form Health Survey instrument. Evidence Synthesis: Five studies were included in the analysis, including 267 patients. The values of the Physiotherapy Evidence Database scale ranged between a minimum of 5 and a maximum of 7 points. Patients with surgically treated AF reported less functionality and physical capacity compared with the nonfractured population. Some patients experienced vitality, emotional, and mental health limitations for a long period. Most surgically treated patients reported no pain and a good health and social status. Conclusion: Limitations in functionality and physical capacity represent the main threats to health-related quality of life in patients with surgically treated AFs.
\end{abstract}

Keywords: SF-36, functionality, lower limbs, physical capacity

\section{Context}

Ankle fractures (AFs) are the most common injuries among the fractures of the lower limbs found in urgency and emergency services. $^{1,2}$ These fractures are a significant source of morbidity for both the young and elderly population. ${ }^{3,4}$ At a young age, the incidence is higher in men, but the rate per gender reverses after 50 years of age. ${ }^{4,5}$

The incidence of $\mathrm{AF}$ is estimated between 101 fractures per 100,000 inhabitants per year in Europe ${ }^{3,5}$ and 184 fractures per 100,000 inhabitants per year in the United States. ${ }^{6}$ In Finland, AFs are very frequent, with a prevalence of 154 fractures per 100,000 inhabitants per year. ${ }^{7}$ Of these, approximately $53 \%$ are unstable fractures requiring surgical treatment. ${ }^{8}$

The treatment of AF may be conservative when there is no deviation, and may be sustainably managed nonsurgically, with splints or traction, or surgically, where the bone displacement and the instability in the recess of the ankle are treated with open reduction and internal fixation technique using plates, screws, and Kirschner wires. ${ }^{9,10}$ The objective of surgical treatment for AF is to allow the early motion after internal fixation, reduce the total time of treatment, and shorten the time required to return to day-to-day activities. ${ }^{11,12}$

Although patients are routinely released from the formality of orthopedic medical follow-up to 4 to 6 months after the surgical stabilization, some authors claim that even after 3 years, half of the

Ribeiro de Ávila, Bento, Leitão, and Fortuna de Sousa are with Research Center in Sports Sciences, Health Sciences and Human Development (CIDESD), Universidade de Trás-os-Montes e Alto Douro (UTAD), Vila Real, Portugal. Ribeiro de Ávila is also with the Universidade Estácio de Sá (UNESA), Juiz de Fora, Brazil. Bento is also with the Escola Superior de Desporto de Rio Maior, IPS (ESDRMIPS), Santarém, Portugal. Gomes is with the Universidade Federal dos Vales do Jequitinhonha e Mucuri (UFVJM), Diamantina, Brazil. Fortuna de Sousa (nelsons@ utad.pt) is corresponding author. patients still report symptoms of pain, stiffness, swelling, and instability of the ankle joint, which may prevent them from returning to the same level of physical activity they exhibited before the AF. ${ }^{13}$

In addition to body signs and symptoms, an AF has significant negative effects on the quality of life (QOL) of patients, associated with functional disability for numerous activities, particularly in older populations. ${ }^{14}$ In fact, advanced age is considered a negative factor for returning to physical activity up to 1 year after AF. ${ }^{15} \mathrm{It}$ has been reported that patients aged 45 years and older are 3 times less likely to return to their work than younger patients. ${ }^{16}$

The literature points out that the focus of research related to $\mathrm{AF}$ should cover sociodemographic, clinical, and psychosocial predictors related to QOL,${ }^{17}$ in particular when crafting prospective studies. ${ }^{18}$ It is clear that QOL must be a determinant variable to be evaluated when studying AF. ${ }^{17,19}$

Among the instruments used to measure QOL, the 36-Item Short-Form Health Survey (SF-36) is critical for assessing patients with $\mathrm{AF},{ }^{20,21}$ and due to its ability to compare with other populations, ${ }^{22,23}$ it should be the instrument of choice when evaluating the functional recovery of this population. ${ }^{22}$

\section{Objective}

To conduct a systematic review evaluating functional outcomes and the QOL of patients with surgically treated AF compared with the nonfractured population.

\section{Evidence Acquisition}

\section{Study Search and Selection}

A literature review was conducted to identify studies on surgically treated $\mathrm{AF}$, from the perspective of the $\mathrm{QOL}$ of individuals. 
The search period in the databases ranged between September 13, 2015 and August 2, 2016, conducted by 2 independent authors (V.R.d.A. and W.F.G.), without any limit of dates of publication. The following databases were surveyed: MEDLINE (PubMed), Embase, Scirus, Scopus (Elsevier), and the Cochrane Central Register of Controlled Trials.

The keywords and Boolean operators used included: ankle fracture OR ankle injuries AND operative fixation OR internal fixation OR open reduction AND 36-Item Short-Form Health Survey OR SF-36. All the work of revision was oriented according to the Preferred Reporting Items for Systematic reviews and Meta-Analyses protocol. ${ }^{24}$

There was no need to directly contact the authors of the studies selected during the search. The lists of references of the complete articles selected were reviewed, but no relevant studies were found matching the theme of this article.

Studies were eligible for inclusion if they: contained only subjects with unstable AF treated surgically; used the SF-36 to assess QOL and function; included the result of all 8 domains of SF-36 questionnaire: functional capacity, physical aspect, bodily pain, general health status, vitality and energy, social aspects, emotional aspect, and mental health; and have been published in the English language. The exclusion criteria were: fractures (stress, pediatric, pathological, calcaneus, tibial pilon, diaphyseal of the tibia and fibula); epidemiologic studies; case reports; review articles; or systematic review.

\section{Assessment of Methodological Quality}

The reviewer (V.R.d.A.), previously trained, assessed the methodological quality of each study selected $(n=5)$ using the Physiotherapy Evidence Database (PEDro) rating scale. ${ }^{25}$

\section{Data Extraction}

The data extracted from the studies were: mean age, population, sample size, gender, study design, follow-up in months, instruments used, fracture classification, cause of fracture, surgical technique, and results of the SF-36 questionnaire.

\section{Evidence Synthesis}

\section{Study Selection}

A total of 235 potentially relevant articles were identified through the search of the database, 5 of which matched the inclusion and exclusion criteria and were considered eligible articles (Figure 1).

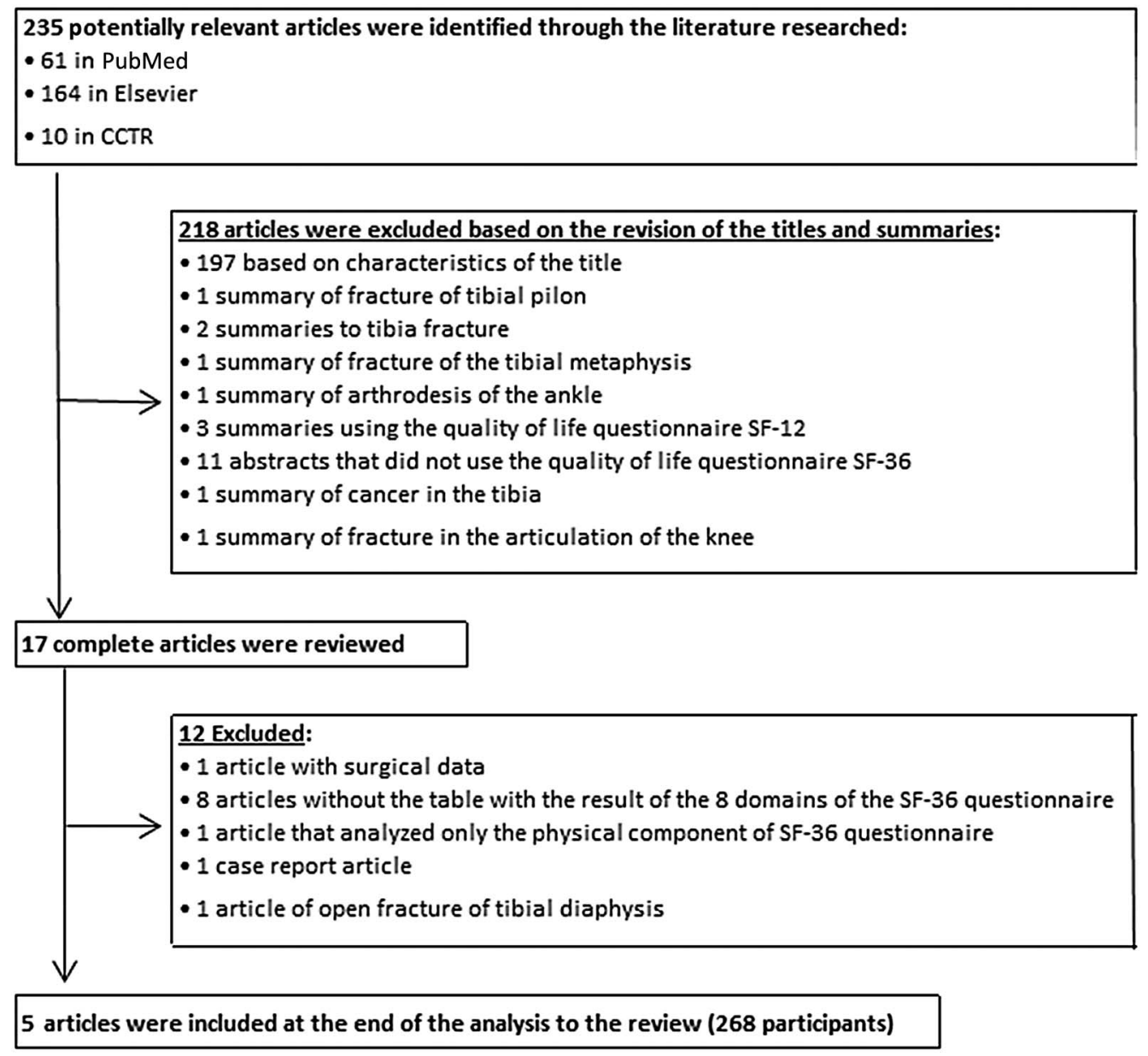

Figure 1 - Diagram of literature search and selection process. CCTR indicates Cochrane Central Register of Controlled Trial; SF-12, 12-Item ShortForm Health Survey; SF-36, 36-Item Short-Form Health Survey. 


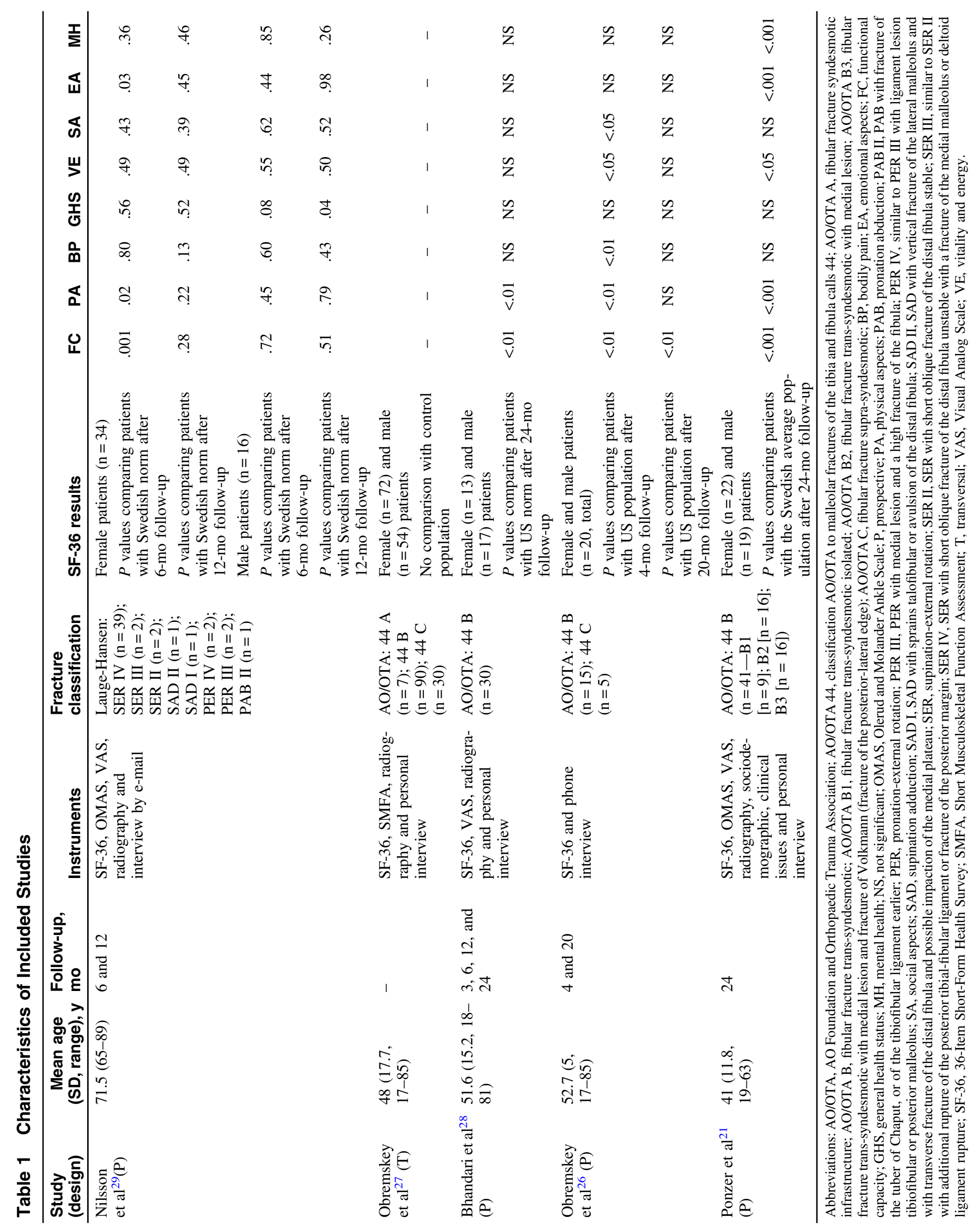


Table 2 Score of Articles According to the Scale of PEDro

\begin{tabular}{|c|c|c|c|c|c|c|}
\hline Study & Nilsson et $\mathrm{al}^{29}$ & Obremskey et al ${ }^{27}$ & Bhandari et $\mathrm{al}^{28}$ & Obremskey et al ${ }^{26}$ & Ponzer et $\mathrm{al}^{21}$ & Total \\
\hline Eligibility criterion & 1 & 1 & 1 & 1 & 1 & 5 \\
\hline Random distribution & 0 & 0 & 0 & 0 & 0 & 0 \\
\hline Distribution concealed & 0 & 0 & 0 & 0 & 0 & 0 \\
\hline $\begin{array}{l}\text { Similar groups in the beginning } \\
\text { of the study }\end{array}$ & 1 & 1 & 1 & 1 & 1 & 5 \\
\hline Subjects blind & 0 & 0 & 0 & 0 & 0 & 0 \\
\hline Therapists blind & 0 & 0 & 0 & 0 & 0 & 0 \\
\hline Evaluators blind & 0 & 0 & 1 & 0 & 1 & 2 \\
\hline Withdrawals & 1 & 0 & 1 & 1 & 1 & 4 \\
\hline Intention of treatment & 1 & 1 & 1 & 1 & 1 & 5 \\
\hline Comparison between groups & 1 & 1 & 1 & 1 & 1 & 5 \\
\hline Measures of precision and variability & 1 & 1 & 1 & 1 & 1 & 5 \\
\hline PEDro score & 6 & 5 & 7 & 6 & 7 & \\
\hline
\end{tabular}

Abbreviation: PEDro, Physiotherapy Evidence Database.

\section{Characteristics of Included Studies}

Of the 5 studies included, 3 studies ${ }^{21,26,27}$ were intended to evaluate the functional results of patients and 2 studies, ${ }^{28,29}$ the QOL. There were 267 total number of participants involved in the 5 studies, but the study by Obremskey et $\mathrm{al}^{26}$ did not report the gender distribution of its sample. A total of 267 fractures were found, with $81 \%$ classified according to the AO Foundation and Orthopaedic Trauma Association ${ }^{21,27,28}$ and $19 \%$ according to Lauge-Hansen classification. ${ }^{29}$ Only the study by Bhandari et $\mathrm{al}^{28}$ reported the kind of fracture, all of which $(n=30)$ were closed fractures. No study referred to the occurrence of fracture side.

Regarding the cause of these fractures, Nilsson et $\mathrm{al}^{29}$ noted that 45 subjects $(90 \%)$ had fractures resulting from falls. Bhandari et $\mathrm{al}^{28}$ and Ponzer et $\mathrm{al}^{21}$ noted that the majority of fractures in their samples, $67 \%$ and $88 \%$, respectively, also resulted from falls. The other studies did not describe the causes of fractures. ${ }^{26,27}$ All the 5 studies ${ }^{21,26-29}$ were reported using the open reduction and internal fixation technique. The other characteristics of studies that constitute the sample of this review are organized in Table 1.

\section{Methodological Quality of the Selected Studies}

There was total agreement for PEDro scores of all reviewed studies. Given that there is no known cutoff value for this scale, the following criteria were used to classify the methodological quality: a score from PEDro equal to or greater than $7(n=2)$ indicates a high methodological quality; scores between 5 and $7 \quad(n=3)$ indicate a moderate methodological quality; and scores below 5 $(\mathrm{n}=0)$ indicate a low methodological quality. The highest PEDro rating was 7 , with an average of 6.2 among the included studies (Table 2).

\section{Data Synthesis}

Among the 5 studies included in this review, 2 studies ${ }^{21,29}$ compared the results of SF-36 with the nonfractured Swedish population (control), 2 studies ${ }^{26,28}$ compared the results with the nonfractured North American population (United States; control), and 1 study ${ }^{27}$ compared the results of the questionnaire SF-36 with the Short Musculoskeletal Function Assessment questionnaire.

In the present systematic review, the majority of patients with surgically treated AF reported significant limitations on functional and physical capacity over time (Figure 2A and 2B). ${ }^{21,26-29}$ As shown in Table 1 , however, one study ${ }^{29}$ reported significant differences in functional and physical capacity only in elderly (65 y and older) female patients $(P=.01$ and $P=.02$, respectively) after a 6-month follow-up, and no differences in elderly male patients. In this last study, both elderly genders reported self-perceived functional and physical capacity after a 12-month follow-up compared with control (Swedish population). Another study that reported differences in physical domain after a 4-month follow-up $(P<.01)$ compared with control (US population) also reported no differences after a 20-month follow-up. ${ }^{26}$

Regarding bodily pain, there were no differences compared with the control population (Figure 2C). One study, ${ }^{26}$ however, showed significant differences in the first 4-month follow-up $(P<.01)$ compared with the control population (US population), but no differences after the 20-month follow-up (see Table 1).

Regarding general health status, the majority of studies reported no differences between the patients with surgically treated AF and control population over time (Figure 2D). However, 1 study $^{29}$ reported significant differences $(P=.04)$ in elderly men after a 1-year follow-up, but not in elderly female patients (Table 1).

As shown in Table 1, the results are not so consistent in the vitality and energy domain, as 2 studies reported no differences ${ }^{28,29}$ and 2 studies reported significant differences. ${ }^{21,26}$ However, all patients with surgically treated AF improved their vitality and energy over time (Figure 2E), and 1 study $^{26}$ that reported significant differences after a 4-month follow-up $(P<.05)$ compared with control also reported no differences after a 20 -month follow-up.

The majority of studies found no differences in social aspects (Figure 2F). One study ${ }^{26}$ reported significant differences after a 4-month follow-up, but no differences after a 20-month follow-up with the same patients (Table 1).

Although the majority of studies showed increasingly higher scores over time for emotional aspects (Figure 2G), only 2 


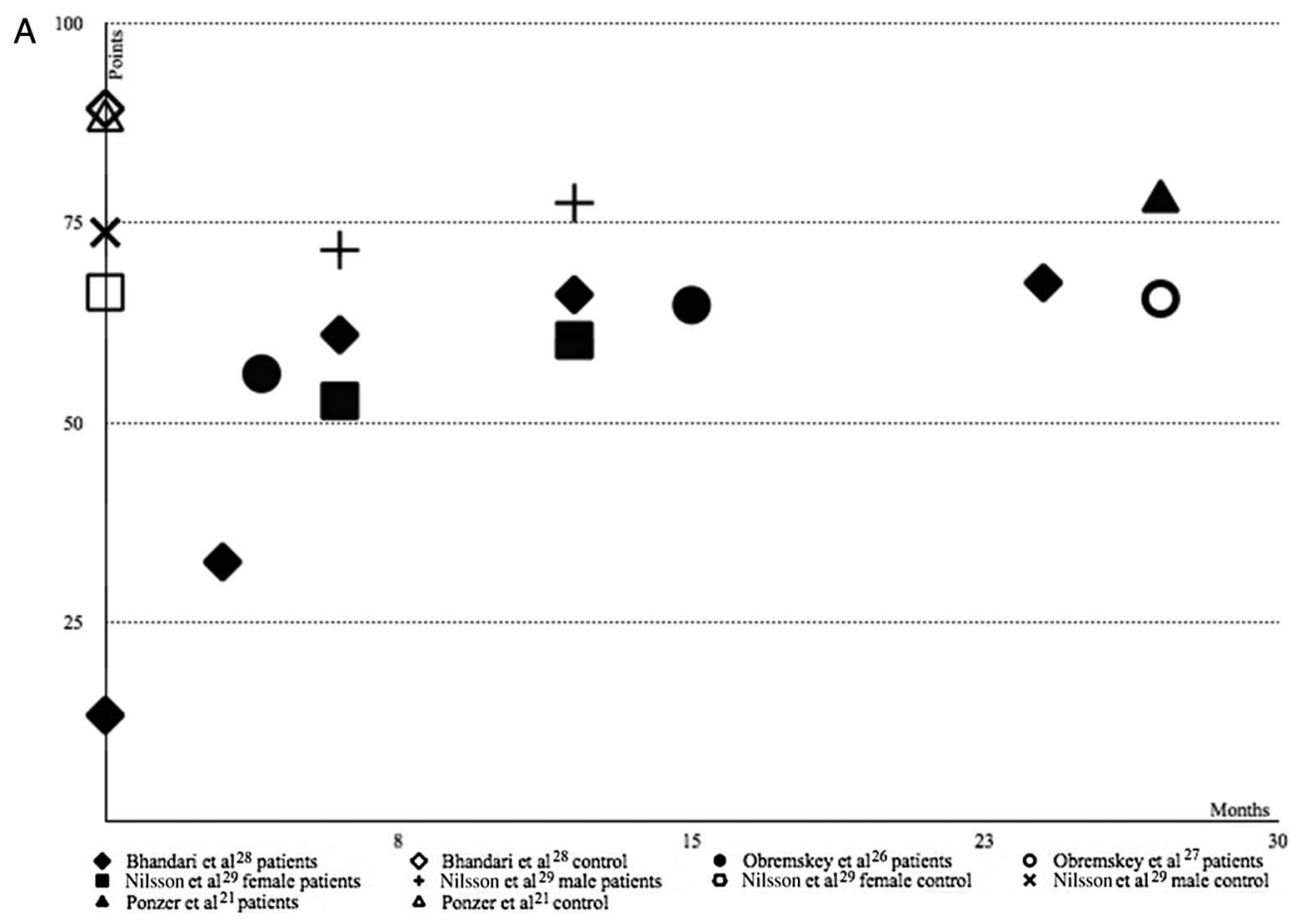

Figure 2 - (A) Functional capacity results after surgically treated AFs over time. (B) Physical aspect results after surgically treated AFs over time. (C) Body pain results after surgically treated AFs over time. (D) General health status results after surgically treated AFs over time. (E) Vitality and energy results after surgically treated AFs over time. (F) Social aspects results after surgically treated AFs over time. (G) Emotional aspects results after surgically treated AFs over time. $(\mathrm{H})$ Mental health results after surgically treated AFs over time. The symbols represent all participants scores (fractured and nonfractured) in the different studies for this domain. y-axis represents the SF-36 questionnaire points (from 0 to 100), and x-axis represents the time (in months) in which the questionnaire was applied.

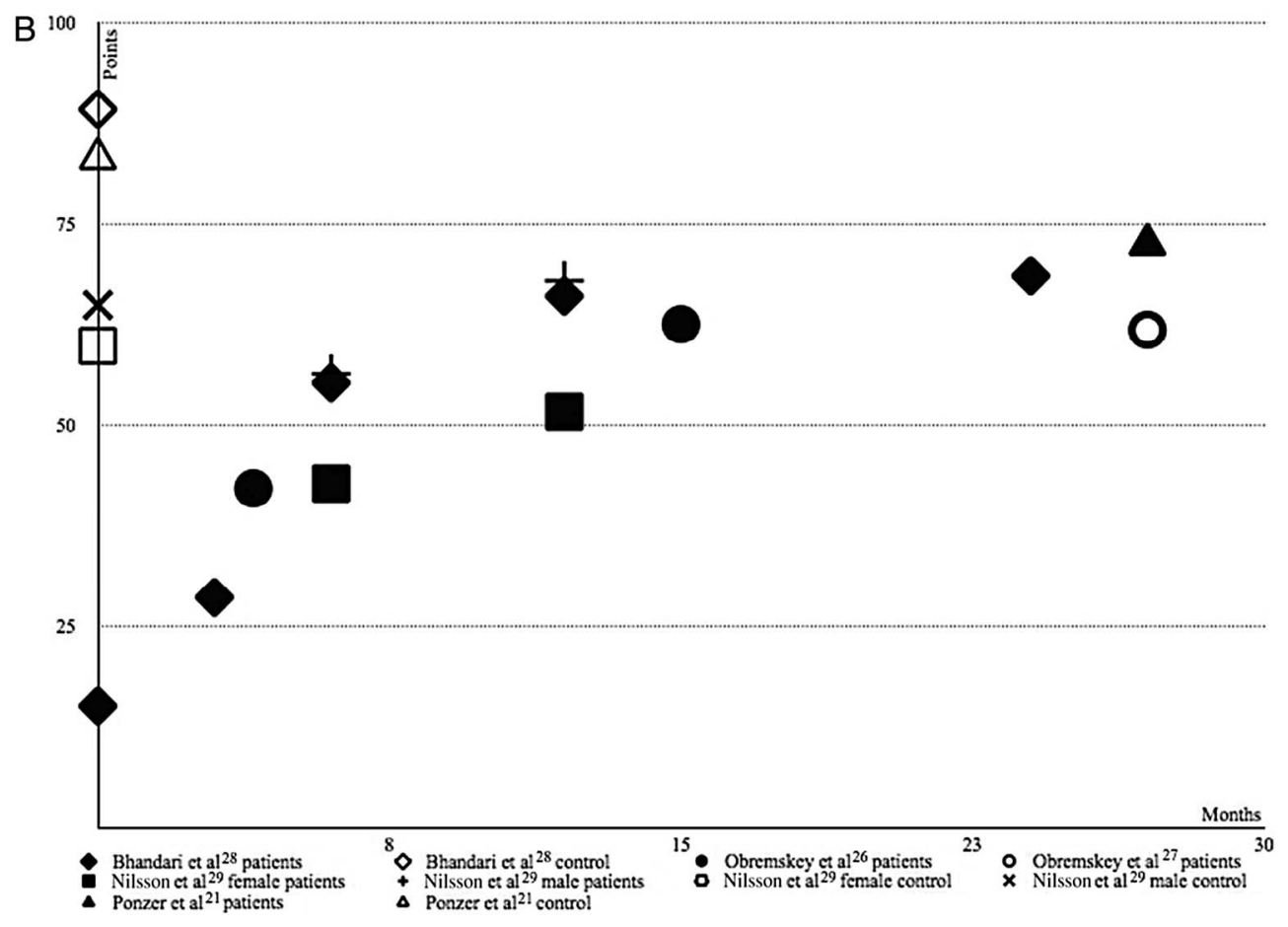

Figure 2 - (Continued) 

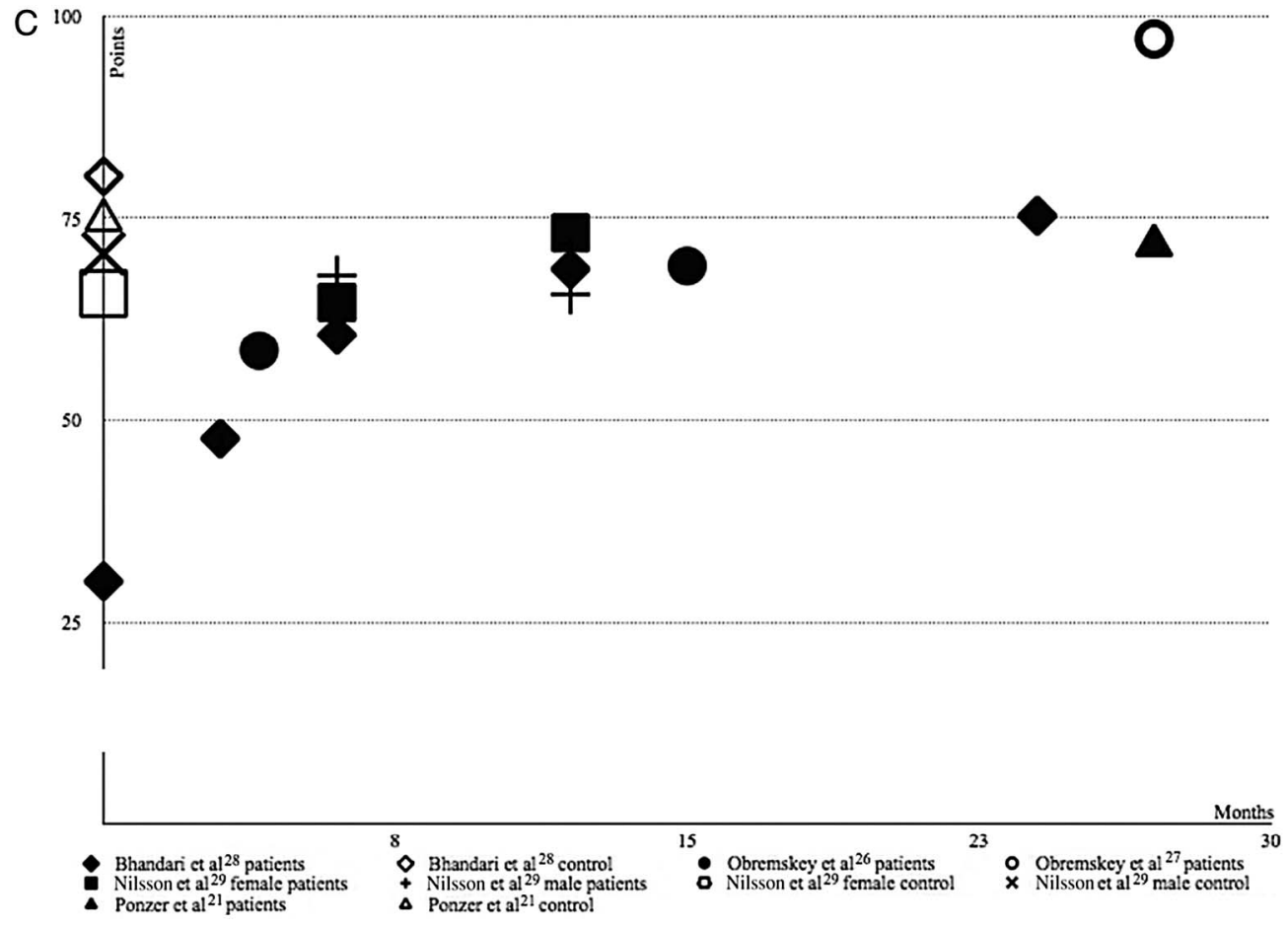

Figure 2 - (Continued)

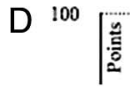

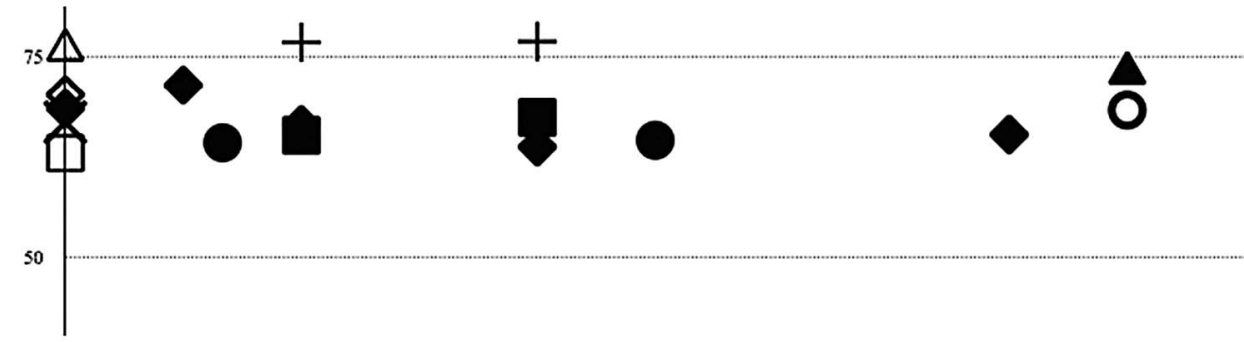

25
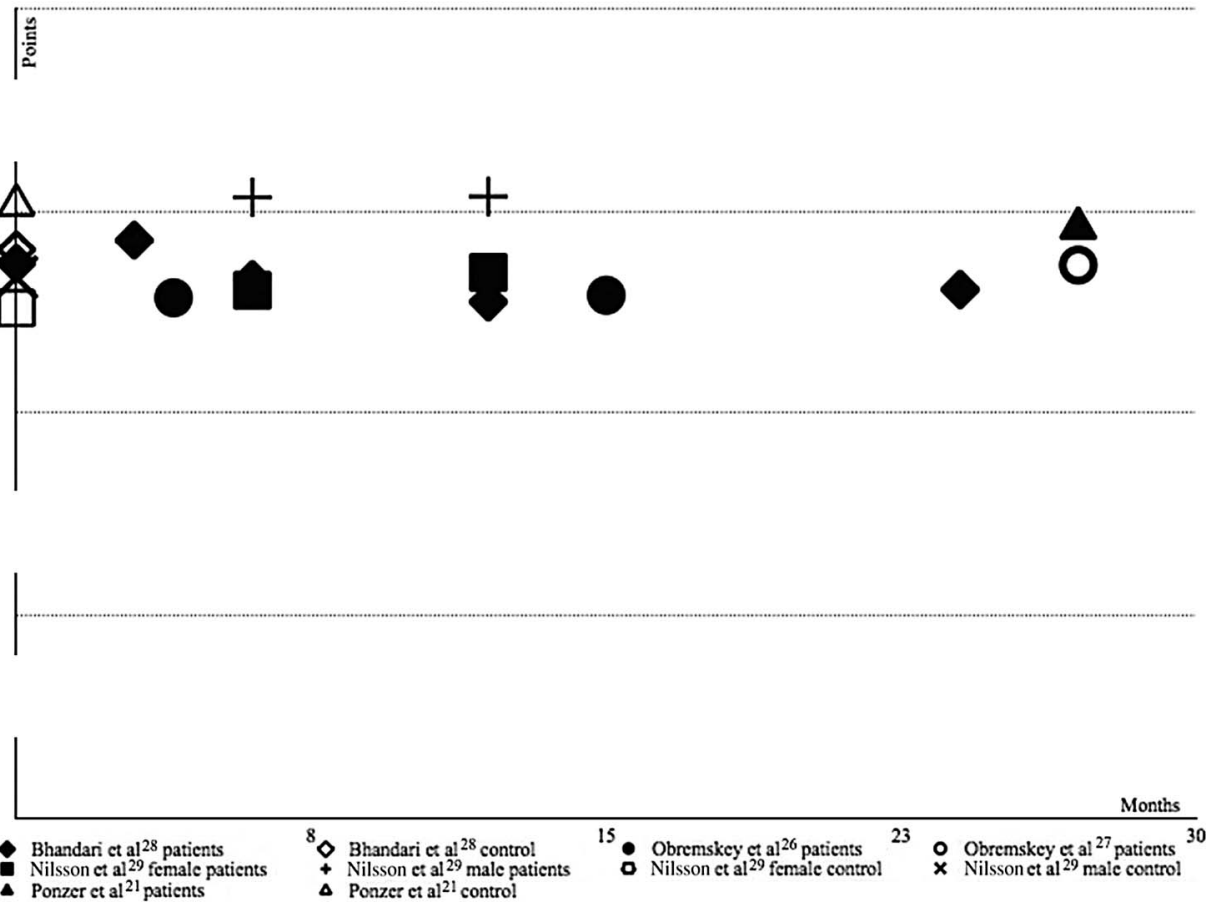

Figure 2 - (Continued)

studies $^{21,29}$ found significant differences (Table 1). One of these studies $^{29}$ showed significant difference only in elderly female patients $(P=.03)$ after a 6-month follow-up, but no differences in the elderly male patients. In this study, all elderly patients (men and women) reported no differences in emotional aspects after a 12-month follow-up. Another study ${ }^{21}$ reported significant differences in this domain after a 2-year follow-up $(P<.001)$. 
$E^{100} \sqrt{\frac{y}{20}}$

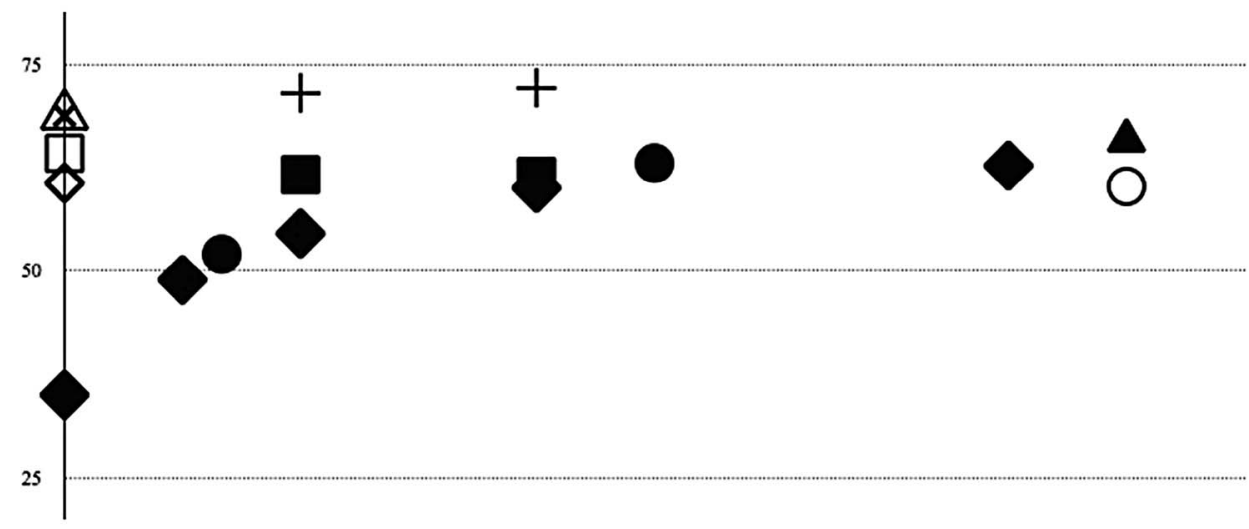

Figure $2-$ (Continued)

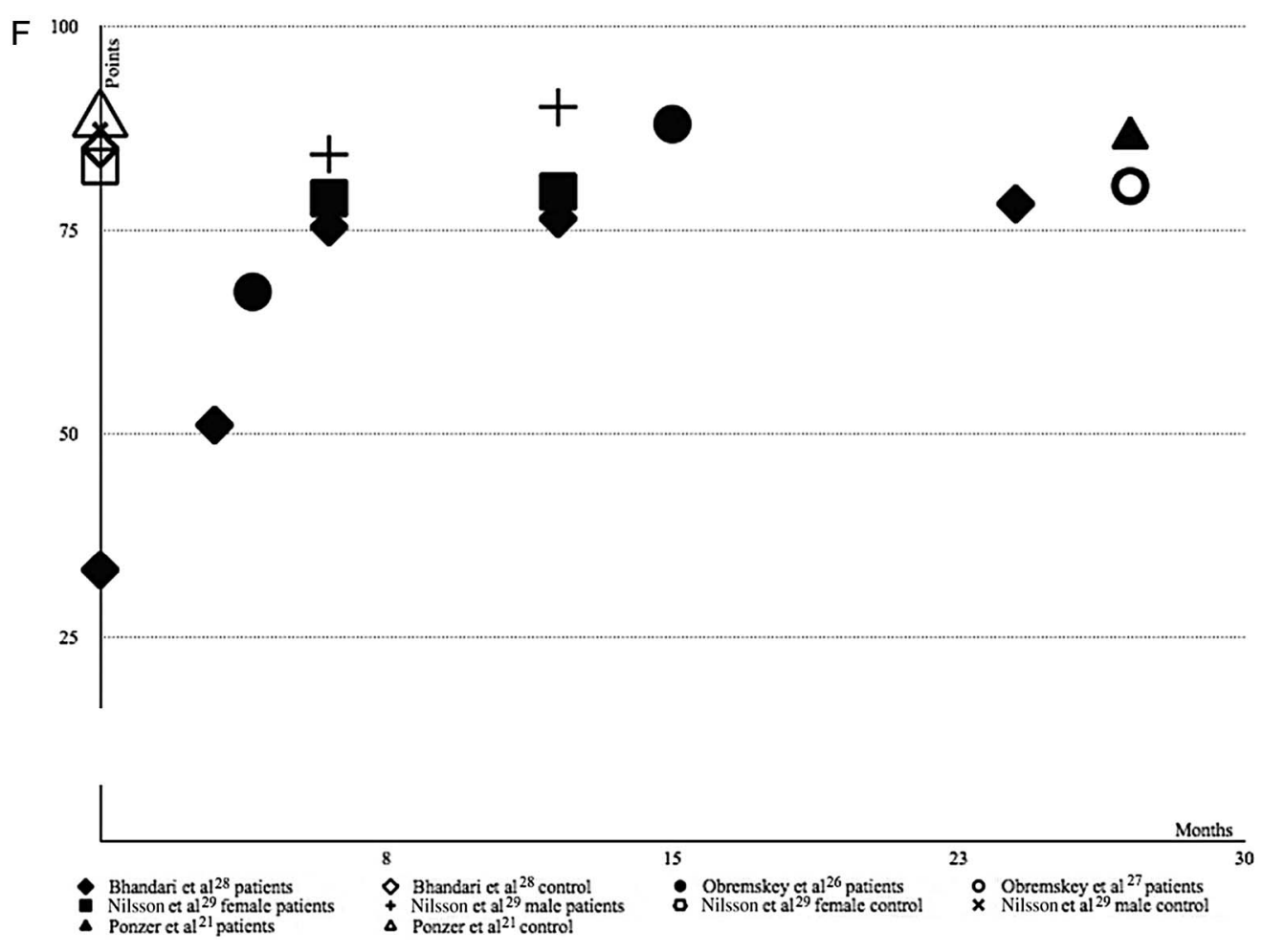

Figure $2-($ Continued $)$

Finally, in the mental health domain, the majority of studies showed only a small oscillation of the scores (Figure 2H). However, 1 study $^{21}$ reported significant differences in this domain after a 2-year follow-up $(P<.001$; Table 1$)$.

\section{Discussion}

This systematic review indicated that functionality and physical aspects are significantly different in patients with surgically treated 

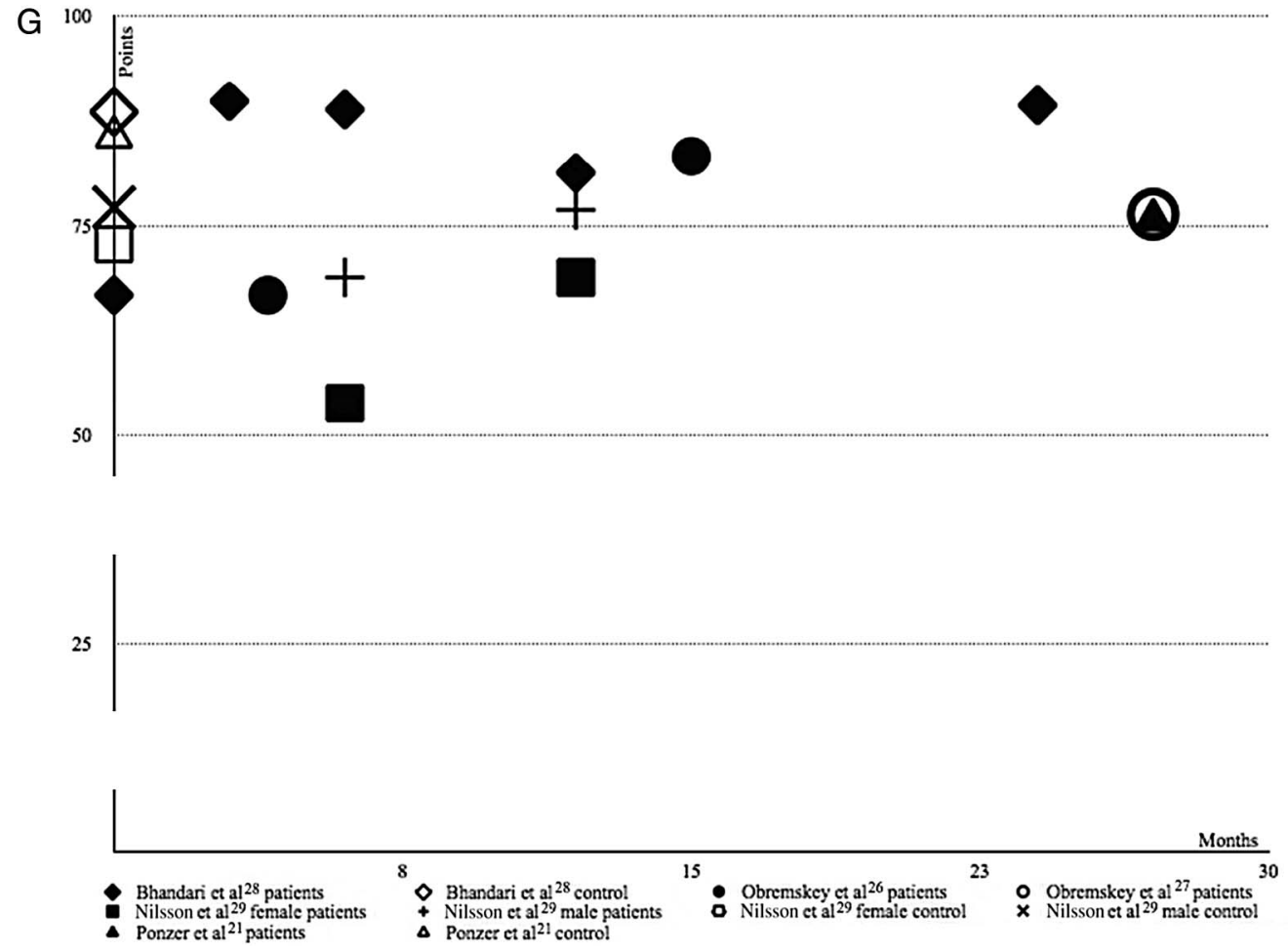

Figure $2-($ Continued $)$

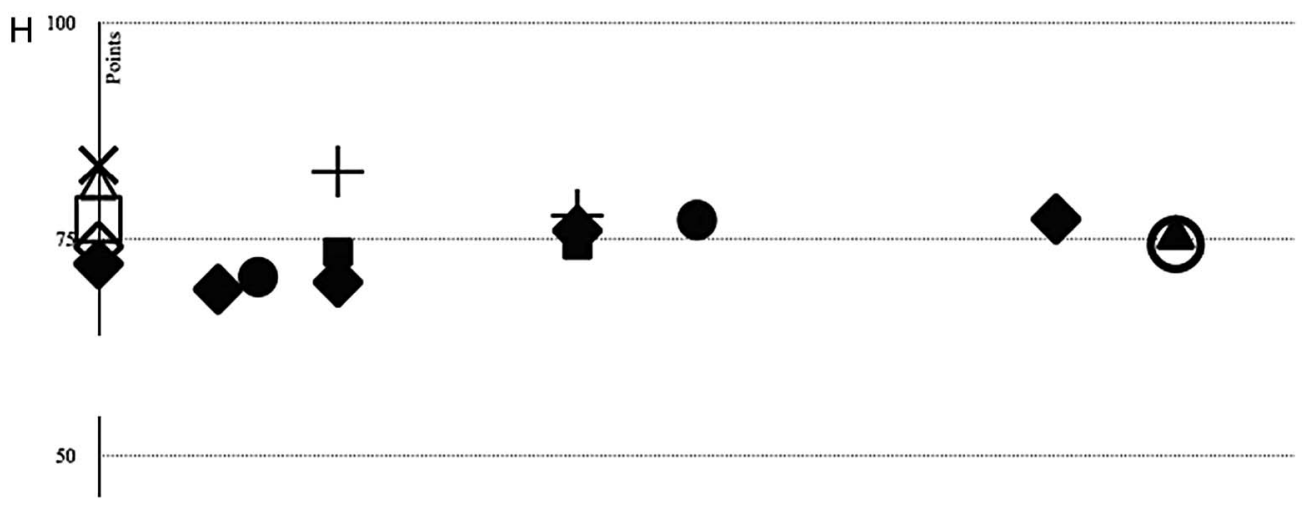

25
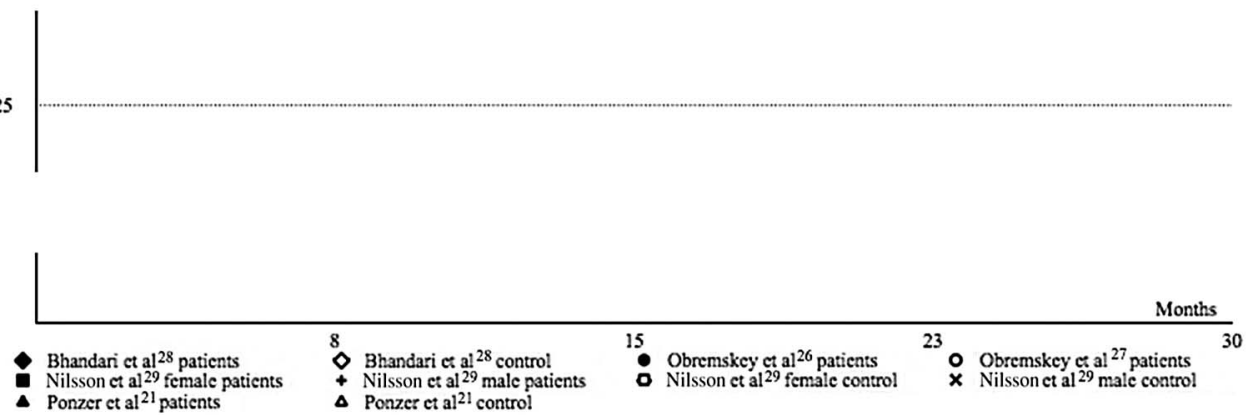

Figure $2-$ (Continued) 
AF over time, although the patients reported no pain. Most patients had a positive self-perception of their general health and social status. Less consistency is reported in the vitality and energy, emotional aspects, and mental health domains, which may represent prolonged limitations.

These findings are similar to other studies ${ }^{30,31}$ in which the patients in recovery after surgically treated AF had progressive functional and physical rehabilitation, which can be a long process. In the present review, 2 studies concluded that patients with surgically treated AF may have functional and physical limitations even 2 years after the injury. ${ }^{21,28}$ These prolonged limitations appear to be particularly related to adult patients rather than elderly patients. In fact, in the Nilsson et al study, ${ }^{29}$ the elderly patients with AF reported functionality and physical capacity similar to the control population (not fractured) only 1 year after injury. This finding contrasts with the results of other studies, where advanced age is associated with worse results in the functional and physical aspect domains of the SF-36. 27,31,32 However, they are similar to other results previously reported. ${ }^{33,34}$ Therefore, the present review supports the idea that most common traumas in the adult population (ie, luxation, open, high-energy, with large soft tissues injury fractures) are more severe, unlike the typical traumas reported in the elderly population (general low-trauma energy resulting from falls). ${ }^{21,28,29}$ Thus, the fracture characteristic (high energy vs low energy) may represent a fundamental aspect in the QOL of patients with surgically treated AF.

Most patients after surgically treated AF reported no bodily pain over time. In fact, only Obremskey et $\mathrm{al}^{26}$ reported significant differences in self-perceived pain after a 4-month follow-up, but no differences were found in the same patients after a 20-month follow-up. It seems likely that bodily pain is not a negative factor in surgically treated AF.

In the general health status domain, only elderly male patients showed a significant difference between measurements after a 1-year follow-up. ${ }^{29}$ Elderly females and adult patients reported values similar or even superior to the control population. . $^{21,26,28,29}$ These results suggest that there are no differences in the perception of patients with AF in their general health status compared with the nonfractured population.

Some studies reported vitality and energy similar to controls in elderly and adults patients with surgically treated AF after 1-2 years of follow-up. ${ }^{26,28,29}$ Others reported significant differences even 2 years after the event that caused the AF. ${ }^{21}$ These results suggest that vitality and energy, inversely related to fatigue, represent domains that improve and even normalize over time, but some patients may report limitations for prolonged periods.

The mental component of the SF-36 related to QOL, which includes social and emotional aspects and mental health, exhibited some influence of these domains. Although the social aspects seem to have no influence on most patients' QOL, emotional aspects and mental health may have a negative impact on the QOL of some patients. Indeed, one study reported significant differences in the emotional and mental aspect domains after a 2-year follow-up $(P<.001$ for both domains $),{ }^{21}$ suggesting that emotional and mental health may be lower than in the nonfractured population.

\section{Limitations}

A key limitation of this systematic review was that functional outcomes were controlled by the SF-36. Another limitation was the great heterogeneity of the participants included in the studies.
However, using the open reduction and internal fixation technique as the surgical treatment and as the inclusion criteria ensured that the gold standard for orthopedic surgeons has been used.

\section{Recommendations for Future Research}

This systematic review combined the results of 268 participants, indicating a small sample size and number of articles included. Therefore, a new review should be conducted where possible, including a meta-analysis. Other instruments to measure functional outcomes should be implemented, perhaps including the 6minute walk test, the 30-second chair test, and the 1-leg stand test to measure walk capacity, lower limbs strength, and balance, respectively.

\section{Conclusion}

Less functionality and lower physical capacity represent the major limitations in patients with surgically treated AF, compared with the nonfractured population. These limitations may prevail for long periods and may become the main threat to the QOL of these patients.

\section{Practice Recommendations}

Long-term functional rehabilitation programs are essential for the recovery and preservation of the QOL in patients surgically treated for $\mathrm{AF}$.

\section{References}

1. Egol KA, Tejwani NC, Walsh MG, Capla EL, Koval KJ. Predictors of short-term functional outcome following ankle fracture surgery. $J$ Bone Joint Surg Am. 2006;88:974-979. PubMed doi:10.2106/JBJS. E.00343

2. Zaghloul A, Haddad B, Barksfield R, Davis B. Early complications of surgery in operative treatment of ankle fractures in those over 60: a review of 186 cases. Injury. 2014;45:780-783. PubMed doi:10.1016/ j.injury.2013.11.008

3. Court-Brown CM, Caesar B. Epidemiology of adult fractures: a review. Injury. 2006;37:691-697. PubMed doi:10.1016/j.injury. 2006.04.130

4. Van Staa TP, Dennison EM, Leufkens HG, Cooper C. Epidemiology of fractures in England and Wales. Bone. 2001;29:517-522. PubMed doi:10.1016/S8756-3282(01)00614-7

5. Jensen SL, Andresen BK, Mencke S, Nielsen PT. Epidemiology of ankle fractures. A prospective population-based study of 212 cases in Aalborg, Denmark. Acta Orthop Scand. 1998;69:48-50. PubMed doi:10.3109/17453679809002356

6. Daly PJ, Fitzgerald RH, Melton LJ, Ilstrup DM. Epidemiology of ankle fractures in Rochester, Minnesota. Acta Orthop Scand. 1987;58:539-544. PubMed doi:10.3109/17453678709146395

7. Pakarinen HJ, Flinkkil TE, Ohtonen PP, Ristiniemi JY. Stability criteria for nonoperative ankle fracture management. Foot Ankle Int. 2011;32:141-147. PubMed doi:10.3113/FAI.2011.0141

8. Manoukian D, Leivadiotou D, Williams W. Is early operative fixation of unstable ankle fractures cost effective? Comparison of the cost of early versus late surgery. Eur J Orthop Surg Traumatol. 2013;23: 835-837. PubMed doi:10.1007/s00590-012-1059-z

9. Cedell CA. Supination-outward rotation injuries of the ankle: a clinical and roentgenological study with special reference to the 
operative treatment. Acta Orthop Scand. 1967;38(suppl 110):P142. PubMed

10. Müller ME, Allogöwer M, Schneider R, Willenegger H. Manual of Internal Fixation: Techinique Recommended by AO-Group. Berlin, Germany: Springer-Verlag; 1979.

11. Ahl T, Dalén N, Lundberg A, Bylund C. Early mobilization of operated on ankle fractures: prospective, controlled study of 40 bimalleolar cases. Acta Orthop Scand. 1993;64:95-99. PubMed doi:10.3109/17453679308994541

12. Sondenaa K, Haigaard U, Smith D, Alho A. Immobilization of operated ankle fractures. Acta Orthop Scand. 1986;57:59-61. PubMed doi:10.3109/17453678608993217

13. Nilsson GM, Jonsson K, Ekdahl CS, Eneroth M. Unsatisfactory outcome following surgical intervention of ankle fractures. Foot Ankle Surg. 2005;11:11-16. doi:10.1016/j.fas.2004.10.004

14. Westphal T, Piatek S, Schubert S, Schuschke T, Winckler S. Quality of life after foot injuries. Zentralbl Chir. 2002;127:238-242. PubMed doi:10.1055/s-2002-24244

15. Del Buono A, Smith R, Coco M, Woolley L, Denaro V, Maffulli N. Return to sports after ankle fractures: a systematic review. $\mathrm{Br} \mathrm{Med}$ Bull. 2013;106:179-191. PubMed doi:10.1093/bmb/lds039

16. Mackenzie EJ, Morris JA, Jurkovich GJ, et al. Return to work following injury: the role of economic, social, and job-related factors. Am J Public Health. 1998;88:1630-1637. PubMed doi:10.2105/ AJPH.88.11.1630

17. Van Son MA, De Vries J, Roukema JA, Oudsten BL. Health status, health-related quality of life, and quality of life following ankle fractures: a systematic review. Injury. 2013;44:1391-1402. PubMed doi:10.1016/j.injury.2013.02.018

18. Stufkens SA, Bekerom MP, Kerkhoffs GM, Hintermann B, van Dijk CN. Long-term outcome after 1822 operatively treated ankle fractures: a systematic review of the literature. Injury. 2011;42:119-127. PubMed doi:10.1016/j.injury.2010.04.006

19. Black JD, Bhavikatti M, Al-Hadithy N, Hakmi A, Kitson J. Early weight-bearing in operatively fixed ankle fractures: a systematic review. Foot. 2013;23:78-85. doi:10.1016/j.foot.2013.05.002

20. Brazier E, Harper R, Jones NM, et al. Validating the SF-36 health survey questionnaire: new outcome measure for primary care. $B M J$. 1992;305:160-164. PubMed doi:10.1136/bmj.305.6846.160

21. Ponzer S, Nåsell H, Bergman B, Törnkvist H. Functional outcome and quality of life in patients with Type B ankle fractures: a two-year follow-up study. J Orthop Trauma. 1999;13:363-368. PubMed doi:10.1097/00005131-199906000-00007

22. Busse JW, Bhandari M, Guyatt GH, et al. Use of both Short Musculoskeletal Function Assessment questionnaire and Short Form-36 among tibial-fracture patients was redundant. J Clin
Epidemiol. 2009;62:1210-1217. PubMed doi:10.1016/j.jclinepi. 2009.01.014

23. Ware JEJ, Sherbourne CD. The MOS 36-Item Short-Form Health Survey (SF-36): conceptual framework and item selection. Med Care. 1992;30:205-209.

24. Moher D, Liberati A, Tetzlaff J, Altman D. Preferred reporting items for systematic reviews and meta-analyses: the PRISMA statement. Ann Intern Med. 2009;151:264-269. PubMed doi:10.7326/00034819-151-4-200908180-00135

25. Morton NA. The PEDro scale is a valid measure of the methodological quality of clinical trials: a demographic study. Aust J Physiother. 2009;55:129-133. PubMed doi:10.1016/S0004-9514(09)70043-1

26. Obremskey WT, Dirschl DR, Crowther JD, Craig WL III, Driver RE, LeCroy M. Change over time of SF-36 functional outcomes for operatively treated unstable ankle fractures. J Orthop Trauma. 2002;16:30-33. PubMed doi:10.1097/00005131-200201000-00007

27. Obremskey WT, Brown O, Driver R, Dirschl DR. Comparison of SF36 and Short Musculoskeletal Functional Assessment in recovery from fixation of unstable ankle fractures. Orthopedics. 2007;30: $145-151$.

28. Bhandari M, Sprague S, Hanson B, et al. Health-related quality of life following operative treatment of unstable ankle fractures: a prospective observational study. J Orthop Trauma. 2004;18:338-345. PubMed doi:10.1097/00005131-200407000-00002

29. Nilsson G, Jonsson K, Ekdahl C, Eneroth M. Outcome and quality of life after surgical treated ankle fractures in patients 65 year or older. BMC Musculoskelet Disord. 2007;8:127. doi:10.1186/1471-2474-8127

30. Bauer M, Bergström B, Hemborg A, Sandegård J. Malleolar fractures: nonoperative versus operative treatment. A controlled study. Clin Orthop Relat Res. 1985;119:17-27.

31. Philips WA, Schwartz HS, Keller CS, et al. A prospective, randomized study of the management of severe ankle fractures. J Bone Joint Surg Am. 1985;67:67-78. doi:10.2106/00004623-198567010-00010

32. Belcher GL, Radomisli TE, Abate JA, Stabile LA, Trafton PG. Functional outcome analysis of operatively treated malleolar fractures. J Orthop Trauma. 1997;11:106-109. PubMed doi:10.1097/ 00005131-199702000-00007

33. Debnath UK, Maripuri SN, Guha AR, Parfitt D, Fournier C, Hariharan K. Open grade III "floating ankle" injuries: a report of eight cases with review of literature. Arch Orthop Trauma Surg. 2007;127:625-631. PubMed doi:10.1007/s00402-007-0314-y

34. El-Shazly M, Dalby-Ball J, Burton M, Saleh M. The use of transarticular and extra-articular external fixation for management of distal tibial intra-articular fractures. Injury. 2001;32(suppl 4):99-106. doi:10.1016/S0020-1383(01)00159-0 